This item was submitted to Loughborough's Research Repository by the author.

Items in Figshare are protected by copyright, with all rights reserved, unless otherwise indicated.

\title{
Compositional effects in nanostructured yttria partially stabilised zirconia
}

PLEASE CITE THE PUBLISHED VERSION

http://dx.doi.org/10.1111/j.1744-7402.2010.02503.x

\section{PUBLISHER}

Wiley / @ American Ceramic Society

VERSION

AM (Accepted Manuscript)

LICENCE

CC BY-NC-ND 4.0

\section{REPOSITORY RECORD}

Binner, J.G.P., Bala Vaidhyanathan, Anish Paul, Ketharam Annaporani, and Bala P.C. Raghupathy. 2015. "Compositional Effects in Nanostructured Yttria Partially Stabilised Zirconia". figshare.

https://hdl.handle.net/2134/18060. 


\title{
Applied
Ceramic \\ TECHNOLOGY
}

Ceramic Product Development and Commercialization

\section{Compositional Effects in Nanostructured Yttria Partially Stabilized Zirconia}

\author{
Jon Binner, ${ }^{\star}$ Bala Vaidhyanathan, Anish Paul, Ketharam Annaporani, and \\ Bala Raghupathy
}

Department of Materials, Loughborough University, Loughborough, LE11 3TU, U.K.

There is a considerable current interest in learning how to process genuinely nanostructured ceramics as they offer the potential for significantly enhanced properties; however, it is often difficult to make large enough components to allow more than the most basic of property measurements. In this work, densified components measuring up to $50 \mathrm{~mm}$ in size have been produced and a number of very interesting properties have been measured and demonstrated.

High solids content but low viscosity yttria-doped partially stabilized zirconia (YSZ) nanosuspensions have been slip cast into $\sim 52 \%$ dense, very homogeneous green bodies in sizes up to $60 \mathrm{~mm}$ in diameter and also granulated using spray freeze drying. When a combustible additive was incorporated with the latter, very flowable granulated nanopowders were achieved that could be die pressed into homogeneous, $\sim 54 \%$ dense bodies at pressures as low as $250 \mathrm{MPa}$. Successful densification has been achieved using hybrid (microwave/ conventional) two-stage sintering yielding densities $>99.5 \%$ of theoretical while retaining a mean grain size of $<100 \mathrm{~nm}$. The strength of the nanoceramics has

*j.binner@lboro.ac.uk

(C) 2010 The American Ceramic Society been found to be very similar to that of conventional submicrometer ceramics, viz. $\sim 1 \mathrm{GPa}$, although the fracture mechanism was different. Two toughness measurement approaches have been used, indentation and surface crack in flexure (SCF). The results indicate that the nano $1.5 \mathrm{YSZ}$ ceramics may be best viewed as crack, or damage, initiation resistant rather than crack propagation resistant; indentation toughness measurements as high as $14.5 \mathrm{MPa} \mathrm{m}^{1 / 2}$ were observed. MicroRaman mapping was demonstrated to be a very effective technique to map the phase transformations in zirconia. The wear mechanism of nanozirconia has been observed to be different compared with that in conventional, submicrometer YSZ and the wear rates to be lower, particularly under wet conditions. In addition, and potentially most usefully, the nano 3 YSZ ceramics 
appear to be completely immune to hydrothermal aging for up to 2 weeks at $245^{\circ} \mathrm{C}$ and 7 bar; conditions that see a conventional, commercial submicrometer ceramic disintegrate completely within $1 \mathrm{~h}$.

\section{Introduction}

The current interest in nanocrystalline ceramics, materials with mean grain sizes $<100 \mathrm{~nm}$, lies in the unique properties they are expected to possess. As the grain size becomes smaller, a greater fraction of the atoms reside on the grain boundaries resulting in the latter increasingly dominating the behavior of the ceramics. ${ }^{1}$ For example, nanocrystalline ceramics can deform both plastically and extensively at elevated temperatures by grain-boundary sliding. ${ }^{2-4}$ There are also indications that some nanostructured ceramics can have an extremely low thermal conductivity, ${ }^{5}$ higher diffusivity, ${ }^{6}$ specific heat capacity and thermal expansion coefficient (CTE), and enhanced ionic and electronic conductivity, ${ }^{7-9}$ while hardness tests indicate that they are softer than coarser grained ceramics at room temperature and tend to crack less easily. ${ }^{10}$ As a result of their many grain boundaries and short diffusional paths, nanoceramics have also been used as solid-state bonding agents to join together other larger grained commercial ceramics at moderate temperatures. ${ }^{11,12}$

Further potential advantages are the energy savings and the ability to co-fire with metals, which should result from the lower temperatures necessary for sintering. Because the finer the particle size the higher the free energy, ${ }^{13}$ the driving force for sintering is also significantly enhanced. However, this increase will also be accompanied by a similar increase in the driving force for grain growth, resulting in difficulty in retaining a nanostructure after the sintering process. Indeed, there are three main challenges to achieving the goal of fabricating engineering components from nanopowders, ${ }^{1}$ viz:

- the low-cost production of quantities of nanopowders with controlled agglomeration;

- the compaction of the particles to achieve flawfree, homogeneous, high green density bodies before sintering (i.e., avoiding cracks, pores, and density gradients); and

- the maximization of densification and minimization of grain growth during sintering.

This paper presents the latest results obtained by the team at Loughborough University associated with the processing and properties of nanostructured YSZ, placing them in the context of ongoing work worldwide. The paper focuses particularly on the effect of the yttria content as it is known that a significant change in mean grain size will affect the stabilization of the different crystallographic phases present in zirconia. ${ }^{14,15}$ This grain-sizedependent shift in the phase boundary composition for nano-YSZ leads to over stabilization of the tetragonal phase at the normal $3 \mathrm{~mol} \%$ yttria content yielding the need to reoptimize the dopant level for optimum mechanical property performance while also providing some other potentially very exciting properties.

\section{Experimental Procedure}

\section{Processing}

The zirconia nanopowders were obtained in the form of $\sim 7 \mathrm{vol} \%$ aqueous suspensions (MEL Chemicals, Manchester, U.K.) with no dispersants or other additives present. They consisted of $1.5,2$, and $3 \mathrm{~mol} \%$ yttria-doped nanoparticles of $\sim 20 \mathrm{~nm}$ mean particle size. The processing steps used to create fully dense, nanostructured ceramics from the precursor suspensions have been described in detail elsewhere ${ }^{16}$; set out below is a brief summary of the key stages of the process.

Concentration of Precursor Nanosuspension: The as-received suspensions had a solids contents of $\sim 7 \mathrm{vol} \%$ and were acidic in nature $(\mathrm{pH} \sim 2.4)$. For the subsequent processing into green bodies, whether by wet or dry forming routes, the solids content of the suspension required raising to $\sim 20 \mathrm{vol} \%$. Extensive work has resulted in a route ${ }^{17}$ that requires the $\mathrm{pH}$ to be shifted to an alkaline value, to $\mathrm{pH} \sim 11$, to permit the use of the anionic dispersant triammonium citrate (TAC, Fisher Scientific, Loughborough, U.K.). The $\mathrm{pH}$ was modified using tetra methyl ammonium hydroxide (TMAH, Aldrich Chemicals, Dorset, U.K.) using $3 \mathrm{wt} \%$ of the latter and then concentration was achieved by evaporation at $60^{\circ} \mathrm{C}$ under continuous stirring while exposing the suspension to ultrasound (Soniprep 150 Ultrasonicator, MSE Scientific Instruments, Manchester, U.K.) at regular intervals to assist in breaking up any agglomerates present. This resulted in a low viscosity, but high solids content suspension that was suitable for further processing into green bodies.

Green Forming: Green bodies were prepared by either slip casting the concentrated nanozirconia suspensions 
described above or by granulating them via spray freeze drying and then die pressing.

For slip casting, the molds were made of a very fine grade of plaster of Paris (Millecast, Lafarge Prestia, Mériel, France). Initially, cavities were machined into cast blocks of plaster of Paris; however, it was soon determined that the surface finish was insufficient and lead to cracking of the cast samples. To prepare molds with a better surface finish, PVC inserts were used and the plaster of Paris slurry poured around them. After allowing the slurry to harden for $1 \mathrm{~h}$, the PVC block was removed and the mold dried in an oven at $60^{\circ} \mathrm{C}$ for $24 \mathrm{~h}$ before being cleaned using an air jet. Any molds with visible defects were rejected; those remaining were used to produce circular slip cast samples measuring up to $60 \mathrm{~mm}$ in diameter before drying ( $\sim 4$ times larger than attempted previously ${ }^{16}$ ) and typically $4-5 \mathrm{~mm}$ thick.

The mold containing the cast samples was left under laboratory conditions for up to $72 \mathrm{~h}$ to allow the initial drying of the body. After this stage, the samples were removed from the mold cavity and placed on a Teflon sheet, to achieve minimal resistance to shrinkage and hence keep drying stresses to a minimum, for $48 \mathrm{~h}$ while the body continued to dry further. After drying, the organics (TAC and TMAH) were removed using a heating cycle based on their TGAs; it consisted of heating the cast green bodies at $0.5^{\circ} \mathrm{C} / \mathrm{min}$ to $700^{\circ} \mathrm{C}$ with $30 \mathrm{~min}$ holds at $100^{\circ} \mathrm{C}, 200^{\circ} \mathrm{C}, 300^{\circ} \mathrm{C}$, and $400^{\circ} \mathrm{C}$ before a final $2 \mathrm{~h}$ hold. The samples were then cooled back down to room temperature using a cooling rate of $0.5^{\circ} \mathrm{C} / \mathrm{min}$. All samples were thoroughly visually inspected for any defects or cracks before being sintered.

Previous work ${ }^{16}$ has shown that the key to success for the production of high density, nanostructured green bodies by die pressing is the production of soft granules that flow well but which crush during pressing. At Loughborough, attention has been focused on spray freeze drying. Using a VirTis ${ }^{\circledR}$ Benchtop $2 \mathrm{~K}$ spray freeze dryer (SP Industries, Gardiner, NY), the freshly ultrasonicated (and thus thoroughly homogeneous) suspension was poured into liquid nitrogen via an ultrasonic rod, the latter breaking up the suspension into droplets. The frozen granules were then transferred to a vacuum dryer that operates at $\sim 13.3 \mathrm{~Pa}$ (100 mTorr) and $-50^{\circ} \mathrm{C}$, the drying of the granules via sublimation of the water taking $\sim 2$ days. Previous results have shown that the solids content of the precursor nanosuspension is crucial for producing a flowable, crushable, dry nanopowder ${ }^{16}$; however, the earlier work still yielded either a powder that was insufficiently flowable for manufacturing industry's automated presses or was too strong to crush without the use of pressures in excess of $400 \mathrm{MPa}$, well above the values typically used by the technical ceramics industry.

To weaken the strength of the agglomerates, foaming agents were added to the suspensions before spray freeze drying, the idea being to create defects in the granule structure, thereby weakening them to improve their crushability while having negligible impact on their flowability. A range of different foaming agents were investigated at different addition levels (Annapoorani et al., unpublished data); the best was found to be $1-2 \mathrm{wt} \%$ additions of Freon 11 (flurotrichloromethane; Fisher Scientific U.K.). After spray freeze drying, the powders were sieved to extract the fraction between 125 and $250 \mu \mathrm{m}$ (to maximize flowability) and then heat treated at $70^{\circ} \mathrm{C}$ for $1 \mathrm{~h}$ to burn off the Freon. The flowability was measured using a Hall flow meter with orifices ranging in size from 2 to $8 \mathrm{~mm}$ and the strengths of individual granules were measured at the Fraunhofer Institut Keramische Technologien und Systeme in Dresden, Germany, using a Manual Granulate Strength Testing System (etewe GmbH, Karlsruhe, Germany). Compaction to form green bodies measuring typically $3-4 \mathrm{~mm}$ thick was via die pressing using a $10 \mathrm{~mm}$ diameter hardened steel die and pressures ranging from 125 to $500 \mathrm{MPa}$.

Densification: The green bodies formed by either slip casting or die pressing were sintered using a two-step sintering cycle where the samples were heated to a high initial temperature, known as T1, held at this temperature for a very short period of time $(6 \mathrm{~s})$, before being cooled down to a lower temperature, known as T2, where they were held for typically $3 \mathrm{~h}$ so that complete densification was achieved. As described previously, ${ }^{16}$ sintering was performed using a hybrid microwave/radiant sintering furnace that could be operated in either pure radiant or hybrid microwave/radiant mode. The microwave frequency was $2.45 \mathrm{GHz}$; up to $2 \mathrm{~kW}$ of microwave power was available. In the work reported here, a fixed level of $600 \mathrm{~W}$ of microwaves was used throughout the sintering cycle, with the amount of radiant power being varied to yield the desired temperaturetime profile. The temperature was measured and controlled using an optical fiber thermometer (Accufiber Model 100, Luxtron, Santa Clara, CA), which previous work has shown is the most accurate method under microwave heating environments; use of a thermal 
imaging camera has indicated that the use of hybrid heating can keep temperature distributions to $\leq 10^{\circ} \mathrm{C}^{18}$

Submicrometer Samples: For comparative purposes, submicrometer 3 YSZ zirconia powder (grade TZ-3 YSBC, Tosoh Europe, Amsterdam, The Netherlands) was die pressed into $10 \mathrm{~mm}$ diameter disks measuring $\sim 3.5 \mathrm{~mm}$ thick using the same hardened steel die used for the nanopowders and a pressure of $160 \mathrm{MPa}$. These bodies were sintered using a single-stage sintering process in a standard radiant furnace (Carbolite, Sheffield, U.K.), at $1500^{\circ} \mathrm{C}$ for $2 \mathrm{~h}$ with heating and cooling rates of $2^{\circ} \mathrm{C} / \mathrm{min}$. According to the manufacturer, the crystallite size of the Tosoh powder was $37 \mathrm{~nm}$, the loss on ignition was $5.4 \%$, and the $\mathrm{Y}_{2} \mathrm{O}_{3}$ content was $3 \mathrm{~mol} \%$.

\section{Characterization}

All of the green and sintered samples were thoroughly characterized in terms of the densities achieved. The green density of the die-pressed compacts was calculated from the mass of the sample $( \pm 0.001 \mathrm{~g})$ and the dimensions of the compact $( \pm 0.01 \mathrm{~mm})$, the latter being measured in at least three locations and averaged. The green density of the slip cast bodies was measured after binder removal using the Archimedes principle using mercury while that of the sintered ceramics was measured using the same technique but using deionized water. The accuracies achieved were $\pm 0.1 \%$ of the theoretical.

Characterization performed on the sintered bodies included scanning electron microscopy (Leo 1530VP FEGSEM, LEO Elektronenskopie, Oberkochen, Germany) of polished (through a series of diamond grinding stages to a final polish using $0.04 \mu \mathrm{m}$ colloidal silica suspension, OP-S, Struers, Solihull, U.K.) and thermally etched ( $6 \mathrm{~min}$ at either T2 for two-stage sintered nanoceramic samples or at $200^{\circ} \mathrm{C}$ below the sintering temperature for the submicrometer samples) samples for grain size using the linear intercept method (ASTM E 112-96). The two-dimensional grain size was converted to three dimensional using a conversion factor of 1.56 . At least three micrographs and a total of 300 grains were evaluated to determine the grain size for each sintered ceramic.

X-ray diffraction (XRD) patterns (model D8 diffractometer, Bruker AXS, Karlsruhe, Germany) were recorded using $\mathrm{Cu} K \alpha$ radiation, $20-80^{\circ} 2 \theta$ range with a step size and step time of $0.02^{\circ}$ and $1 \mathrm{~s}$, respec- tively. The volume fraction of the monoclinic phase, $V_{\mathrm{m}}$, in the various samples was determined by the method of Toraya et al. ${ }^{19}$

$$
\begin{gathered}
V_{m}=\frac{1.311 X_{m}}{1+0.311 X_{m}} \\
X_{m}=\frac{I_{(\overline{1} 11) m}+I_{(111) m}}{I_{(111) t}+I_{(\overline{1} 11) m}+I_{(111) m}}
\end{gathered}
$$

where $X_{m}$ is the integrated intensity ratio and the subscripts $m$ and $t$ represent the monoclinic and tetragonal phases, respectively. The integrated intensity values were calculated using a refinement technique with the help of DiffracPlus and Topas software. A fundamental parameters approach was used for the refinement.

The Vickers micro indentation hardness of the samples was determined as per ASTM E 384, using a Mitutoyo HM-124 micro hardness tester (Mitutoyo, Kawasaki, Japan). A square-based pyramidal-shaped diamond indenter with face angles of $136^{\circ}$ was used with a load of $1 \mathrm{~kg}$ being applied for $15 \mathrm{~s}$. After the removal of the load, the length of the diagonals of the indentation on the samples were measured with the help of a microscope and the Vickers hardness of the samples were calculated using the formula, $H_{\mathrm{V}} \quad(\mathrm{GPa})=$ $0.0018544 \times P / d^{2}$, where $P$ is the force $(\mathrm{N})$ and $d$ is the length of the diagonal of the indentation $(\mathrm{mm})$.

The indentation toughness of the samples was determined using a Mitutoyo AVK-C2 hardness tester (Mitutoyo). The indents on the samples were created using a Vickers pyramidal indenter by applying a $10 \mathrm{~kg}$ load for $15 \mathrm{~s}$; where this was insufficient to generate cracks, a 20 or $30 \mathrm{~kg}$ load was used. After indenting the sample, the length of the diagonal indent and radiating cracks were recorded. The indentation toughness was calculated using the formula suggested by Anstis et al. ${ }^{20}$

$$
K_{\mathbf{I}_{c}}=0.016\left(\frac{E}{H}\right)^{1 / 2} \frac{P}{C^{3 / 2}}
$$

where $E$ is the Young's modulus of the material, $H$ the Vickers hardness, $P$ the indentation load, and $c$ the crack length. The value of $E$ was assumed to be $210 \mathrm{GPa}$ for all the samples. ${ }^{21}$ The indentation toughness was also calculated using a number of other formulas, for example those proposed by Lankford ${ }^{22}$ and Niihara ${ }^{23,24}$ for radial and Palmqvist types of cracks; as expected while they all showed different values they showed the same trend. 
Micro-Raman analysis (LabramHR spectrometer, Horiba Jobin Yvon, Villeneuve d'Ascq, France) was performed to map qualitatively the different phases present in and around the indents. A helium-neon laser (wavelength $632.8 \mathrm{~nm}$ ) was used to excite the sample; the laser power was $20 \mathrm{~mW}$ and the spectrum integration time was $15 \mathrm{~s}$. An average of two spectra was taken from every data point and the spectra were recorded from 100 to $800 \mathrm{~cm}^{-1}$ for spot analysis and from 100 to $350 \mathrm{~cm}^{-1}$ when mapping was performed. The latter range was selected as it was enough to cover the most important peaks corresponding to the monoclinic and tetragonal phases while allowing a more rapid mapping. The spot size for the data collection was $<1 \mu \mathrm{m}$.

Strength and further toughness measurements were also performed at the National Physical Laboratories, NPL, in the United Kingdom. Bars were rough-cut by hand using a diamond saw and then ground into rectangular section test-pieces measuring $2.5 \mathrm{~mm} \times 2 \mathrm{~mm} \times 25 \mathrm{~mm}$ using a 320-grit wheel for the final finishing and grinding parallel to the test-piece length. Chamfers were applied to all four long edges in accordance with the guidelines in ASTM C 1161-02c using a flat lap and 500 grit $\mathrm{SiC}$ paper. For the strength measurements, a semiarticulating fourpoint flexural strength jig was used with inner and outer spans of 6.7 and $20 \mathrm{~mm}$, respectively, and $2.5 \mathrm{~mm}$ diameter tungsten carbide rollers; the design allowed a free movement of the support rollers during loading. The measurements were conducted using an Instron 4505 machine (Instron, Norwood, MA) with the United Kingdom Accreditation Service (UKAS)-accredited load cell calibration and a cross-head displacement rate of $0.2 \mathrm{~mm} / \mathrm{min}$. The peak force at fracture was captured and the nominal flexural strength, $S$, computed using the equation:

$$
S=\frac{3 P L}{4 b d^{2}}
$$

where $P$ is the break force, $L$ is the outer (support span), $b$ is the specimen width, and $d$ is the specimen thickness. Ten samples were tested for each composition and the mean was calculated.

The toughness of the samples was measured by NPL as per ASTM C 1421-01b in the SCF mode. The tests were carried out using the standard flexural strength test specimens described above and a standard set of conditions, viz. three HV40 indentations were placed along the center line of each test piece separated by $\sim 1 \mathrm{~mm}$ using a standard Vickers machine. The test piece was canted sideways at $5^{\circ}$ and tilted lengthwise at $2^{\circ}$ before indentation to make the precrack easier to see and measure. Three indentations were used to cover the problem of variability in the degree of cracking induced. The indentation was ground away to a depth of about $100 \mu \mathrm{m}$ using a 320 grit diamond lap and then the edges of the face were rechamfered to minimize the risks of edge failure. Fracture was achieved using the same four-point test jig and the conditions described above for the strength measurements. The cross-sectional dimensions of the test-piece were measured at the point of fracture with a calibrated micrometer and the precracks and any subcritical crack growth on both halves of the fractured test-piece were photographed at a calibrated magnification. This enabled the precrack and/or subcritical crack growth boundary to be determined either from paper images or a computer screen. The fracture toughness was then computed in accordance with the standard equation:

$$
K_{\mathrm{I}_{s c}}=Y\left[\frac{3 P_{\max }\left[S_{\mathrm{o}}-S_{\mathrm{i}}\right] 10^{-6}}{2 B W^{2}}\right] \sqrt{a}
$$

where $K_{\mathrm{I}_{s c}}$ is the the fracture toughness using the SCF method $\left(\mathrm{MPa} \mathrm{m}^{1 / 2}\right)$; $Y$ is the stress intensity factor coefficient (dimensionless); $P_{\max }$ is the maximum force (break force, N); $S_{0}$ is the outer span $(\mathrm{m}) ; S_{\mathrm{i}}$ is the inner span $(\mathrm{m}) ; B$ is the side-to-side dimension of the test specimen perpendicular to the crack length $(\mathrm{m}) ; W$ is the top-to-bottom dimension of the test specimen parallel to the crack length (m); $a$ is crack depth (m), and $c$ is the crack half width $(\mathrm{m})$. The stress intensity shape factor coefficients were calculated for both the deepest point of the precrack periphery, $Y_{\mathrm{d}}$, and for the point at the surface, $Y_{s}$, and the greater value of these two were taken as $Y$ to calculate the toughness of the material.

Wear testing of the ceramics, both dry and under deionized water, was carried out using a linearly reciprocating ball-on-flat sliding wear as per ASTM G 133-05. The samples were mounted in epoxy resin and polished to a fine surface finish, $\sim 30 \mathrm{~nm} \mathrm{Ra}$ (average surface roughness parameter) measured using a Talysurf CLI 2000 system (Taylor Hobson, Leicester, U.K.). Twelve-millimeter-diameter tungsten carbidecobalt balls $(5-7 \%$ cobalt) were used as the ball with a constant $20 \mathrm{~N}$ load being applied. The total number of cycles was 100,000 with a $2.5 \mathrm{~cm}$ stroke length, equivalent to a total sliding distance of $5 \mathrm{~km}$. After wear testing, the samples were cleaned using ultrasound in distilled water, followed by acetone and 
then methanol and the weight loss of each sample and the respective ball ( $\mathrm{a}$ fresh ball was used for each test) measured and the wear volume calculated. The wear scar on the zirconia specimens were analyzed using FEGSEM, XRD, and micro-Raman spectroscopy. When the wear testing was carried out under water, the samples were thoroughly dried before recording the weights.

Hydrothermal aging studies were conducted to evaluate the degradation resistance of the various zirconia ceramics. The aging experiments were performed using an autoclave with a PTFE liner containing deionized water and varying the temperature and pressure. The initial aging studies were performed at $140^{\circ} \mathrm{C}$ and 4 bar; these conditions were selected as they are close to those used for hydrothermal aging studies of biomedical-grade zirconia ceramics. ${ }^{25}$ The aging temperature, pressure, and time were subsequently increased up to $245^{\circ} \mathrm{C}$ and 7 bar for 14 days for selected samples. The aged samples were characterized using XRD, microRaman, FEGSEM, and hardness measurements.

\section{Results}

\section{Processing}

Characterization of the precursor nanosuspensions revealed that the 1.5 and 2 YSZ suspensions had slightly broader particle size distributions than that of the 3 YSZ nanosuspension; this might be a result of the presence of both monoclinic and tetragonal phases in the 1.5 and 2 YSZ powders, while the 3 YSZ was $100 \%$ tetragonal. It was also observed that while $2.5 \mathrm{wt} \%$ TAC was appropriate to stabilize the 1.5 and 2 YSZ nanosuspensions for the concentration process, the $3 \mathrm{YSZ}$ suspension required $3 \mathrm{wt} \%$ TAC. The reason for this difference is not well understood at the present time.
Typical slip-cast green bodies measuring $\sim 52 \mathrm{~mm}$ in diameter after drying and removal of the organics (TMAH and TAC) may be seen in Fig. 1; densities were in the range of $50-52 \%$ of theoretical, with the 1.5 and 2 YSZ bodies displaying a slightly denser packing, presumably because of the slightly broader particle size distribution. In order to achieve green bodies that exhibited no evidence of cracking whatsoever, it was found that drying under $80 \%$ relative humidity at $25^{\circ} \mathrm{C}$ was the most appropriate for all the YSZ compositions. While the elevated humidity led to longer drying times, up to 5 days to achieve completely dry bodies, lower humidities resulted in an elevated risk of cracking. It can be seen how smooth the upper surface of the as-cast bodies were; roughness measurements made using a Talysurf indicated that they were typically $\sim 8 \mathrm{~nm}$, which is very close to the $6 \mathrm{~nm}$ value for the surface finish of commercial femoral heads.

Figure 2 shows the granules produced by spray freeze drying using $20 \mathrm{vol} \% 3 \mathrm{YSZ}$ nanosuspension and with and without the use of $1 \mathrm{wt} \%$ Freon 11. It can be clearly seen that while the size and shape of the granules, and hence the flowability, in Fig. 3, is not significantly affected (and hence remains similar to the benchmark), the surface (and the interior) of the granules contains many more defects when the Freon is used. This has the direct effect of weakening the granules and hence allowing them to crush at lower pressures. Figure 4 shows the strength of the individual granules as measured using the Manual Granulate Strength Testing System. Although there is a large degree of scatter in the data, and there also appears to be a size effect that is currently under further investigation, it is clear that the strength of the individual granules has been reduced by a small but significant amount. This reduction in granule strength also translates into the ability to
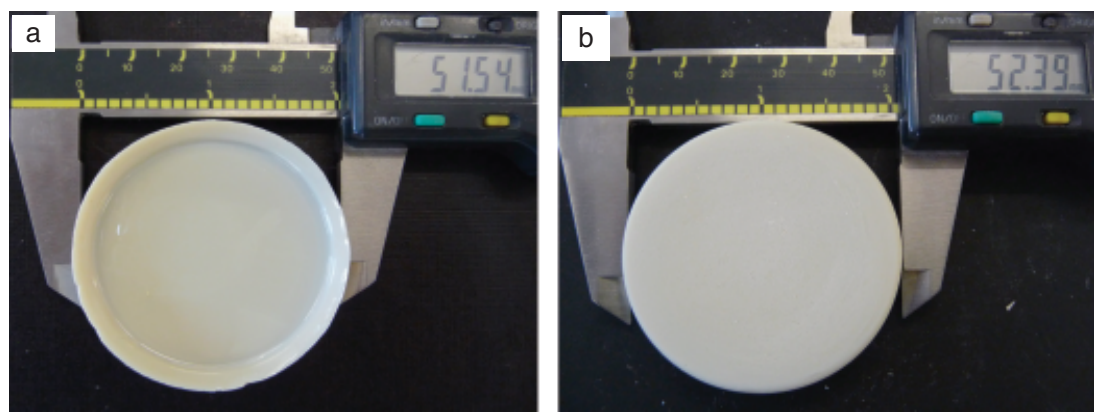

Fig. 1. Slip cast green body after drying and organics removal produced from a $60 \mathrm{~mm}$ diameter mold; (a) top surface and (b) bottom surface. 

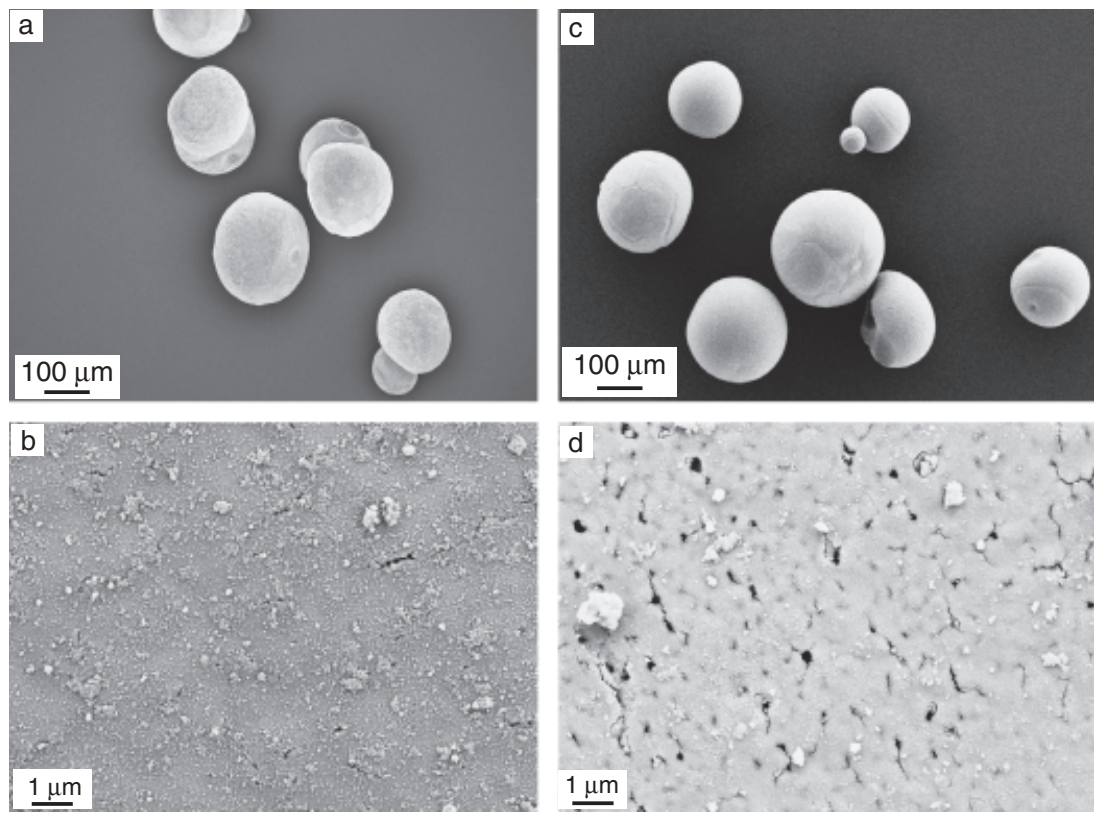

Fig. 2. Spray freeze-dried granules produced from 20 vol\% solids content 3-YSZ nanosuspension, (a) and (b) without Freon, (c) and (d) with $1 w t \%$ Freon and after heat treatment.

achieve higher green densities at a given pressure used in die pressing, Fig. 5. While densities of up to $58 \%$ of the theoretical can be achieved, they require pressures as high as $500 \mathrm{MPa}$; well outside of the range of most ceramic manufacturers unless new equipment is bought (although not outside the range of the existing equipment in the powder metallurgy industry). However, because it is possible to achieve densities $>99 \%$ of the theoretical while retaining a final mean grain size $<100 \mathrm{~nm}$ using dry-pressed green bodies with densi-

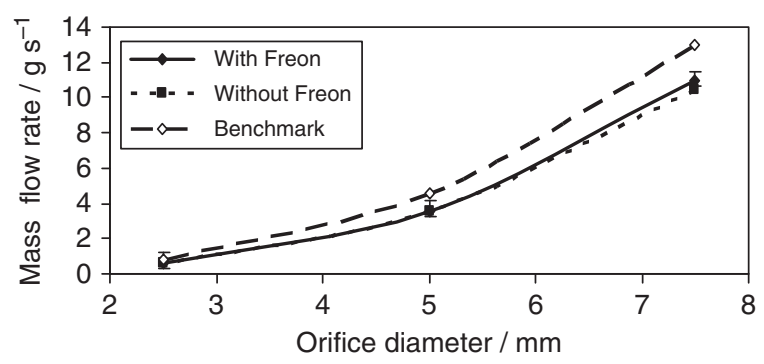

Fig. 3. Flowability of spray freeze-dried granules produced from 20 vol\% 3-YSZ nanosuspension with and without the addition of 1 vol\% Freon 11 and compared with a benchmark commercial submicrometer spray dried powder. ties as low as $54 \%$ of the theoretical, this means that pressures as low as $250 \mathrm{MPa}$ (within the capability of most ceramic manufacturers using current equipment) can be used with the Freon-based granules. The approach of incorporating additives within the suspension to weaken the resulting granules is now the subject of a patent application. $^{26}$

Figure 6 shows fracture surfaces of green bodies pressed from granulated powders with and without the use of $1 \mathrm{wt} \%$ Freon. It is readily apparent that even at

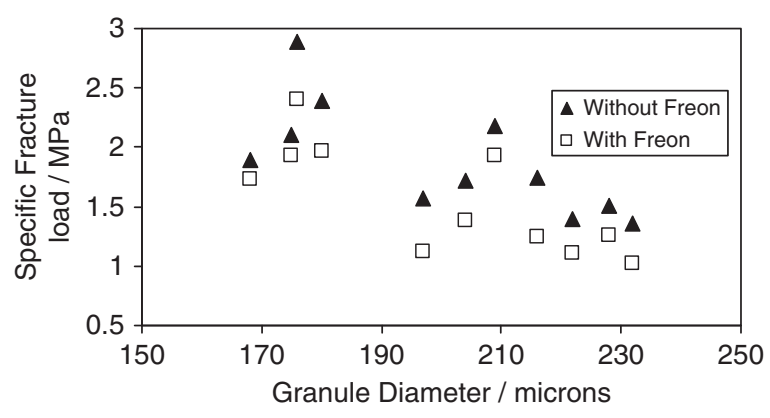

Fig. 4. Results of single granule strength measurements for spray freeze-dried powders produced from 20 vol\% 3-YSZ nanosuspension with and without 1 vol\% Freon 11. 


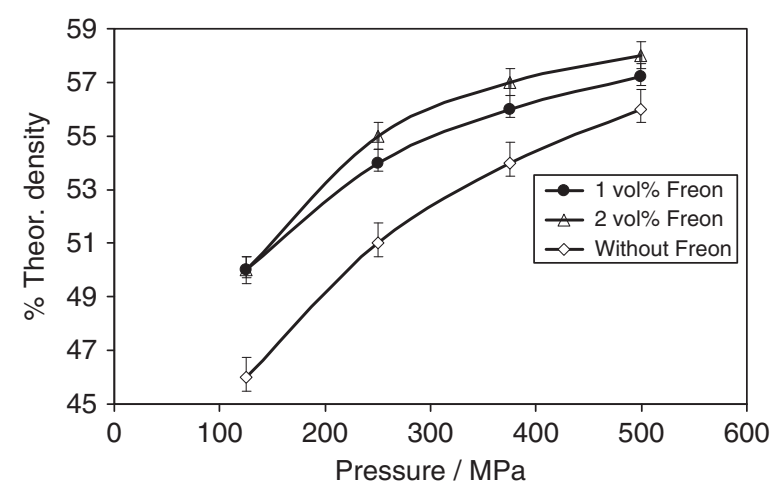

Fig. 5. Compaction characteristics of spray freeze-dried powders containing additions of Freon 11 to reduce the strength of the constituent granules.

$380 \mathrm{MPa}$, the granules do not crush entirely when the Freon is not used while there was no evidence of residual granule relics when the Freon was used at the lower pressure of just $250 \mathrm{MPa}$, a result confirmed by mercury porosimetry (Annapoorani et al., unpublished data). Finally, it was apparent during the pressing trials that these granulated powders displayed no tendency to stick to the dies and the pellets were all produced with no evidence of delamination or capping problems.

It was already known ${ }^{16}$ that it is possible to use the combination of a two-step sintering and microwave hybrid heating to achieve densities in excess of $99 \%$ of the theoretical while retaining a final mean grain size of $<100 \mathrm{~nm}$ for the 3 YSZ nanoparticles. The optimum sintering conditions of $6 \mathrm{~s}$ at $1150^{\circ} \mathrm{C}$ (T1) followed by $3 \mathrm{~h}$ at $1050^{\circ} \mathrm{C}$ (T2) for the slip-cast bodies yielded densities of $\sim 99.5 \%$ of the theoretical and a final mean grain size of $\sim 65 \mathrm{~nm}$. However, for the
1.5 YSZ and 2 YSZ nanoceramic compositions, it was found that the two-step sintering cycle needed modification to allow for the variation in yttria content. ${ }^{27}$ In general, the lower the yttria level, the less demanding the sintering conditions required, a result also observed by Vasylkiv et $a l,{ }^{28}$ Luo et $a l,{ }^{29}$ and Huang et al. ${ }^{30}$ The latter suggested that the difference in densification rates between the samples with different $\mathrm{Y}_{2} \mathrm{O}_{3}$ content was attributed to the influence and magnitude of the associated grain-growth process.

\section{Properties}

The XRD patterns of the sintered ceramics revealed that there was no monoclinic content present in either the nano 2- or $3 \mathrm{YSZ}$ or the commercial submicrometer ceramic after sintering, while the nano $1.5 \mathrm{YSZ}$ was calculated to contain 36.6 vol $\%$ monoclinic. Broadly similar results were obtained from the micro-Raman results. ${ }^{27}$

Figure 7 shows the results of the Vickers microindentation hardness measurements plotted against the sintered sample density. Each data point is the average of at least 10 indents and all the indents were created by applying a $1 \mathrm{~kg}(9.81 \mathrm{~N})$ load. The trend is very clear, with the hardness increasing almost linearly with density for all the ceramics, although a slight decrease in hardness may be observed near the maximum density. A linear increase in hardness with density has also been reported by Cottom and Mayo ${ }^{31}$ for nano- and submicrometer 3 YSZ and by Bravo-Leon et al. ${ }^{32}$ for nano 0 YSZ, 1 YSZ, and 1.5 YSZ. Vasylkiv et al. ${ }^{28}$ reported a slight decrease in hardness for nanozirconia samples when the density reached $>99.5 \%$. Comparing the hardness values of the samples with different yttria contents, the maximum value of hardness was observed
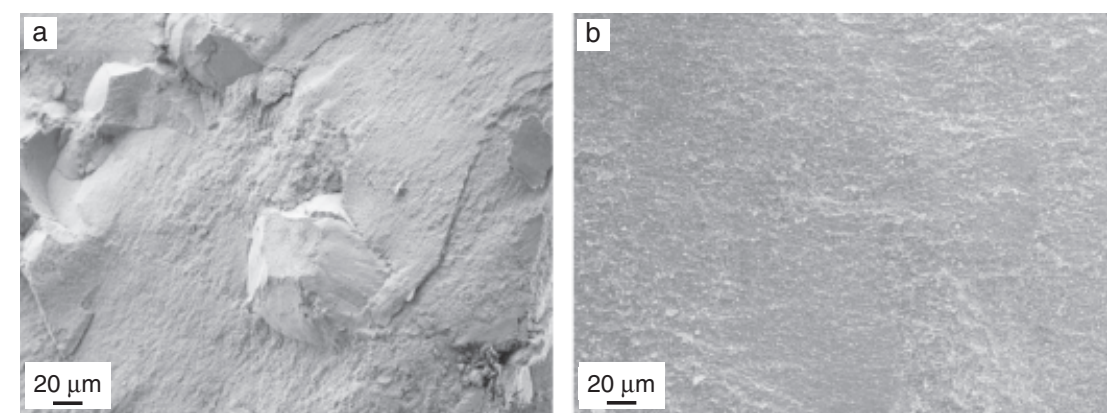

Fig. 6. FEGSEM images of fractured surfaces of compacts pressed from sieved 3-YSZ spray freeze-dried powders, (a) without Freon and pressed at $380 \mathrm{MPa}$ and (b) with 1 vol\% Freon and pressed at $250 \mathrm{MPa}$. 


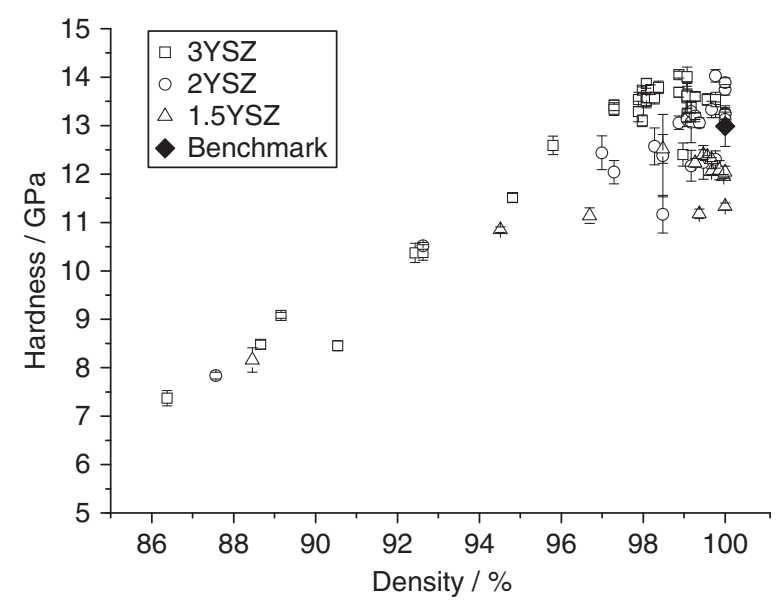

Fig. 7. Variation in microhardness with density for nano YSZ ceramics with different yttria contents and a commercial submicrometer 3 YSZ ceramic.

for the nano 3 YSZ and 2 YSZ ceramics, both were 14.0 GPa, with the nano 1.5 YSZ ceramic being somewhat lower at $12.5 \mathrm{GPa}$. This is opposite to the trend reported by Vasylkiv et al. ${ }^{28}$ but matches that observed by Bravo-Leon et al. ${ }^{32}$ Compared with the benchmark commercial submicrometer ceramic, the nano 2- and 3 YSZ ceramics were very slightly harder; Cottom and Mayo ${ }^{31}$ observed them to be slightly less hard. However, the degree of scatter is such that no strong conclusions may be drawn.

The strength of the selected samples, measured at NPL, are summarized in Table I; they are each the mean of 10 samples. Broadly, the values were very similar although the nano 3 YSZ were the lowest in strength. Given the degree of scatter in the data, it must be concluded that there was no significant difference in strength between the nano $1.5 \mathrm{YSZ}$ and the submicrom-

Table I. Strength Values Obtained for Three Different YSZ Grades Produced by Slip Casting

\begin{tabular}{lc}
\hline Sample & Flexural strength (MPa) \\
\hline Nano 1.5 YSZ & $1088 \pm 153$ \\
Nano 3 YSZ & $922 \pm 155$ \\
Benchmark 3 YSZ & $1040 \pm 257$ \\
\hline
\end{tabular}

YSZ, yttria-doped partially stabilized zirconia. eter benchmark 3 YSZ ceramics. Typical fracture surfaces may be seen in Fig. 8; the fracture mode was found to be intergranular for all the nanosamples and transgranular for the benchmark ceramics. This result is supported by scanning electron microscopy performed on the nanoceramics in the early stages of this work when variable grain sizes throughout the samples were common. It was observed that large grains underwent transgranular fracture, Fig. 9, while the finer grains underwent intergranular cracking.

The variation in indentation toughness with density is shown in Fig. 10, while that with grain size is presented in Fig. 11. The maximum values measured for the different ceramic grades are summarized in Table II together with the corresponding grain size and density values and the toughness results obtained by NPL using the SCF technique. As indicated earlier, all the indentation toughness measurements were carried out using a $10 \mathrm{~kg}$ load except for the nano $1.5 \mathrm{YSZ}$ where a $30 \mathrm{~kg}$ load was used; no correction has been made to the values for this change. From Fig. 10, it can be seen how important it is to obtain a high density; there is no consistent difference in toughness below about $99 \%$ of the theoretical density. Above this value, it can be observed that while the toughness of the nano 3 YSZ sample is lower than that of the benchmark submicrometer ceramic, both the nano 2- and 1.5 YSZ are apparently significantly much tougher with the latter showing indentation toughness values up to nearly $15 \mathrm{MPam}^{1 / 2}$. It is possible that slightly lower yttria levels, for example 1 YSZ, might offer the opportunity for even higher toughness levels; this work is still to be undertaken. The values for both the nano- and submicrometer $3 \mathrm{YSZ}$ s from the present study are similar to results reported in the literature for these ceramics. ${ }^{31}$

Table II reveals that the SCF toughness values are very much lower than those obtained by the indentation technique. While all the values are broadly similar, it is notable that the nano 1.5 YSZ actually exhibits the lowest toughness value. The difference in the two toughness measurements for the nano $1.5 \mathrm{YSZ}$ is expected to arise from the generation of a monoclinic-rich region formed around the precrack after indentation using a $40 \mathrm{~kg}$ load. This will have offered little resistance to further crack propagation in comparison with the highly transformable tetragonal phase present when the indentation toughness measurements were made. This suggests that the nano $1.5 \mathrm{YSZ}$ ceramics may be best viewed as crack, 

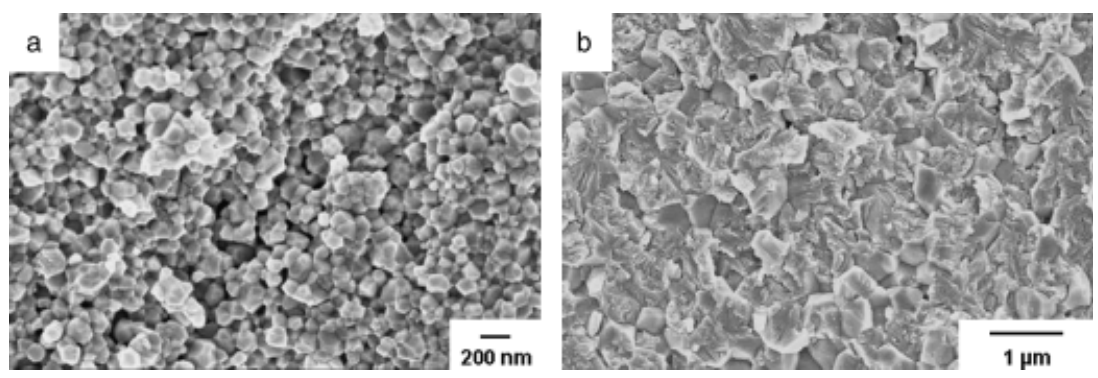

Fig. 8. Fracture surfaces of samples after strength measurement, (a) nano 1.5 YSZ showing intergranular fracture and (b) the benchmark 3 YSZ ceramic showing transgranular fracture.

or damage, initiation resistant rather than crack propagation resistant.

Focusing on the indentation toughness results, the effect of grain size on the toughness of YSZ ceramics is fairly complex, with the transformability of the zirconia increasing with increasing grain size and decreasing yttria content. Thus, it can be assumed that the optimum grain size for the 3 YSZ ceramics to yield their maximum toughness values lay above the investigated grain size range in the present study for either the nanoor submicrometer versions. This is in line with the results reported previously in the literature; Cottom and Mayo $^{31}$ reported maximum toughness for 3 YSZ at a mean gain size $>1 \mu \mathrm{m}$ while Wang et al. ${ }^{33}$ reported a value of $1.4 \mu \mathrm{m}$. Interestingly, in the latter, the maximum toughness for $2.5 \mathrm{YSZ}$ was observed at $1.22 \mu \mathrm{m}$, the trend being in line with the present work.

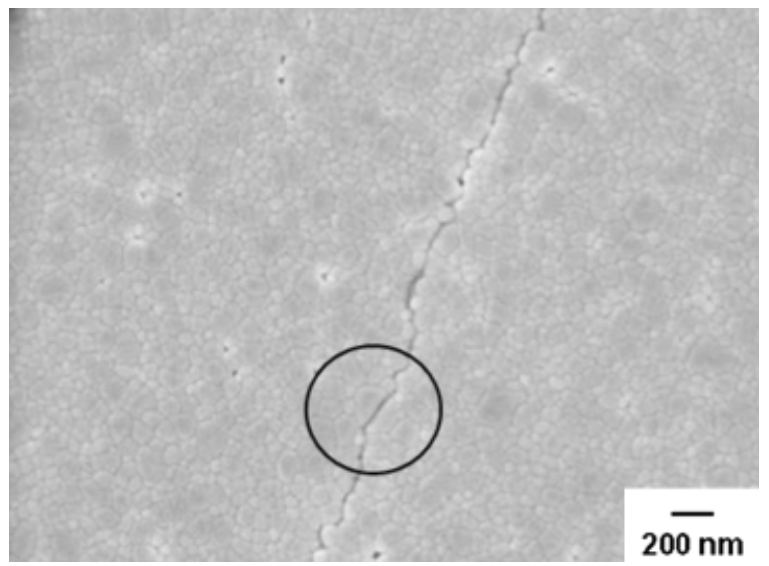

Fig. 9. FEGSEM micrograph showing predominantly intergranular cracking in a nanostructured 3 YSZ ceramic, but with transgranular crack propagation across a large, $0.2 \mu \mathrm{m}$, grain (circled).
Figure 12a shows the location of nine micro-Raman spot analyses performed on each type of ceramic after indenting while Figs. 12b-e show the results of the analyses for the benchmark submicrometer and nano $3 \mathrm{YSZ}$ and nano $1.5 \mathrm{YSZ}$ ceramics, the latter at both 10 and $30 \mathrm{~kg}$ loads. From the spectra for the benchmark (Fig. 12b), it can be observed that phase transformation from tetragonal to monoclinic only occurred at the indent itself; a similar result was observed for the nano $3 \mathrm{YSZ}$ although the degree of transformation appears somewhat smaller. While it should be noted that the results in Fig. 12 cannot be used quantitatively because the different grain sizes will mean that the signal-to-noise ratio will be different between the two ceramics, nevertheless it is logical that a lower degree of transformation would have re-

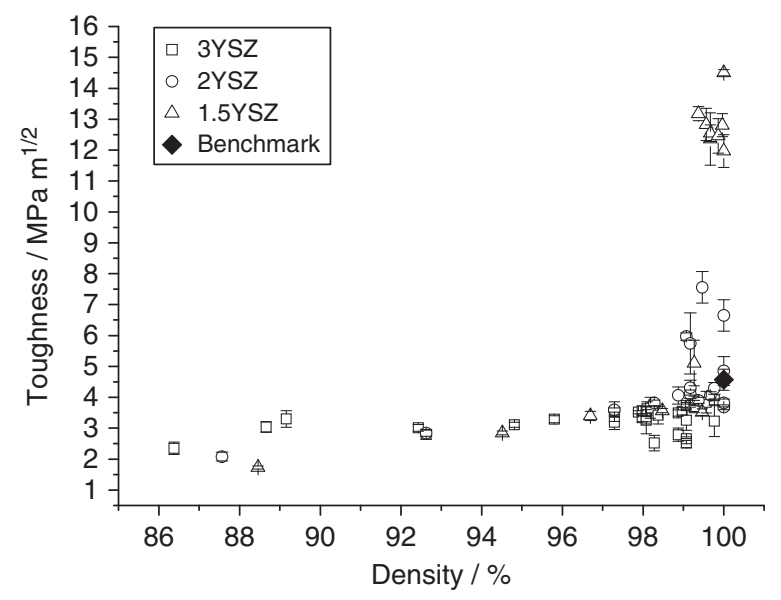

Fig. 10. Variation in indentation toughness with density for nano YSZ ceramics with different yttria contents and a commercial submicrometer 3 YSZ ceramic. Values measured using a $10 \mathrm{~kg}$ load, except the nano 1.5 YSZ which used a $30 \mathrm{~kg}$ load. See text for explanation. 


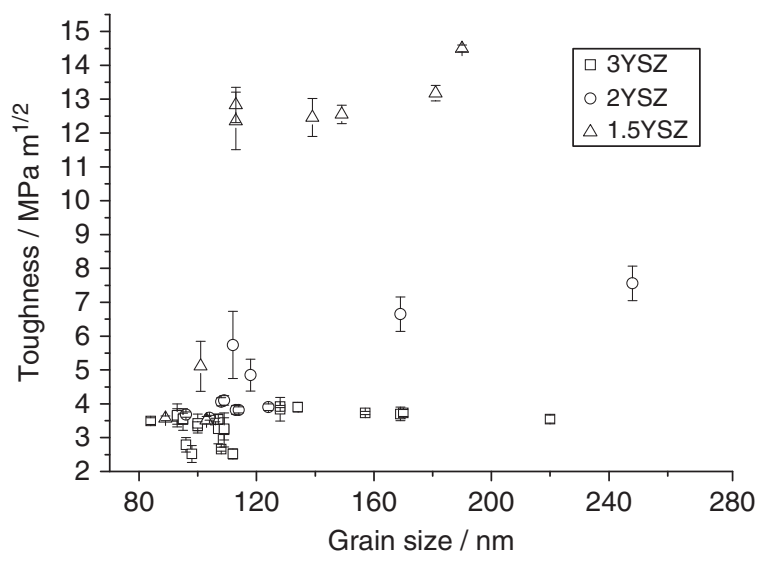

Fig. 11. Variation in indentation toughness with grain size for nano YSZ ceramics with different yttria contents. Values measured using a $10 \mathrm{~kg}$ load, except the nano $1.5 Y S Z$ which used a $30 \mathrm{~kg}$ load. See text for explanation.

duced the ability for crack suppression and hence yielded a lower toughness value.

The behavior of the nano $1.5 \mathrm{YSZ}$ ceramic was found to be completely different from that of the other ceramics in that it did not develop any detectable radial cracks at the $10 \mathrm{~kg}$ load. Nevertheless, the micro-Raman spectra show a significant amount of monoclinic present, both at the indent itself and around it; only spot analyses 1 and 9 show the absence of any monoclinic phase. It is possible that this increased phase transformation prevented the generation of cracks at this load. To generate radial cracks, the indentation load needed to be increased to $30 \mathrm{~kg}$-although even at this value, the crack lengths were much shorter in comparison with the other ceramics $(\sim 10$ vs $\sim 100 \mu \mathrm{m})$. Figure 13a was recorded using the optical microscope with differential interference contrast to highlight the stress patterns. As reported by Kaliszewski et al., ${ }^{34}$ the indentation-in- duced martensitic transformation occurs in a localized zone around the indentation, giving rise to stress fields in the surrounding material resulting from volume misfit. The lines surrounding the indentation are thought to be the lines of maximum shear stress. As they are visible even after the removal of the indenter, it can be assumed that the indentation-induced deformation is accommodated by a permanent, nonelastic mechanism. Once the volume changes due to phase transformation are not enough to contain the stresses due to the applied load, cracks will begin to propagate from the indent corners where the stress concentration is maximum. As long as the applied stresses are below the limit the phase transformation can accommodate, there will be no cracking. A mapped micro-Raman image of the monoclinic present around an indent made using a $30 \mathrm{~kg}$ load in the nano 1.5 YSZ ceramic is shown in Fig. 13b. It can be seen that there is a considerable amount of phase transformation around the indent and the presence of the monoclinic phase close to the propagating cracks is also distinguishable.

Table III summarizes the results of the ball-on-flat reciprocating wear testing of the benchmark and nano 3 YSZ samples under both dry and wet wear conditions. It can be seen that the nanostructured ceramics suffered less wear under both sets of conditions compared with the benchmark material; He et al. ${ }^{35}$ and Yan and Wei ${ }^{36}$ also reported a similar increase in wear resistance with a decreasing grain size. Surprisingly, although there was little difference between wet and dry conditions for the benchmark ceramic, the nano 3 YSZ ceramics performed better when wet than dry. Lee et $a l^{37}$ has reported that there is no decrease in frictional coefficients due to the presence of water, compared with dry sliding in the case of zirconia.

Figure 14 shows FEGSEM micrographs of the turn point area of the samples after the dry wear test; it can be

Table II. Toughness Values Obtained for the Different YSZ Grades Produced by Slip Casting

\begin{tabular}{|c|c|c|c|c|}
\hline Sample & $\begin{array}{l}\text { Indentation toughness } \\
\left(\mathrm{MPa} \mathrm{m}^{1 / 2}\right)\end{array}$ & $\begin{array}{l}\text { SCF toughness } \\
\quad\left(\mathrm{MPa} \mathrm{m}^{1 / 2}\right)\end{array}$ & $\begin{array}{l}\text { Grain size } \\
\quad(\mathbf{n m})\end{array}$ & $\begin{array}{l}\text { Density } \\
\text { (\%TD) }\end{array}$ \\
\hline Nano 1.5 YSZ & 14.5 & 4.7 & 190 & 99.9 \\
\hline Nano 2 YSZ & 7.6 & - & 248 & 99.5 \\
\hline Nano 3 YSZ & 3.9 & 5.3 & 128 & 99.8 \\
\hline Benchmark 3 YSZ & 4.6 & 5.2 & 520 & 99.8 \\
\hline
\end{tabular}

Indentation toughness values measured using a $10 \mathrm{~kg}$ load, except the nano $1.5 \mathrm{YSZ}$ that used a $30 \mathrm{~kg}$ load. See text for explanation.

SCF, surface crack in flexure; YSZ, yttria-doped partially stabilized zirconia. 

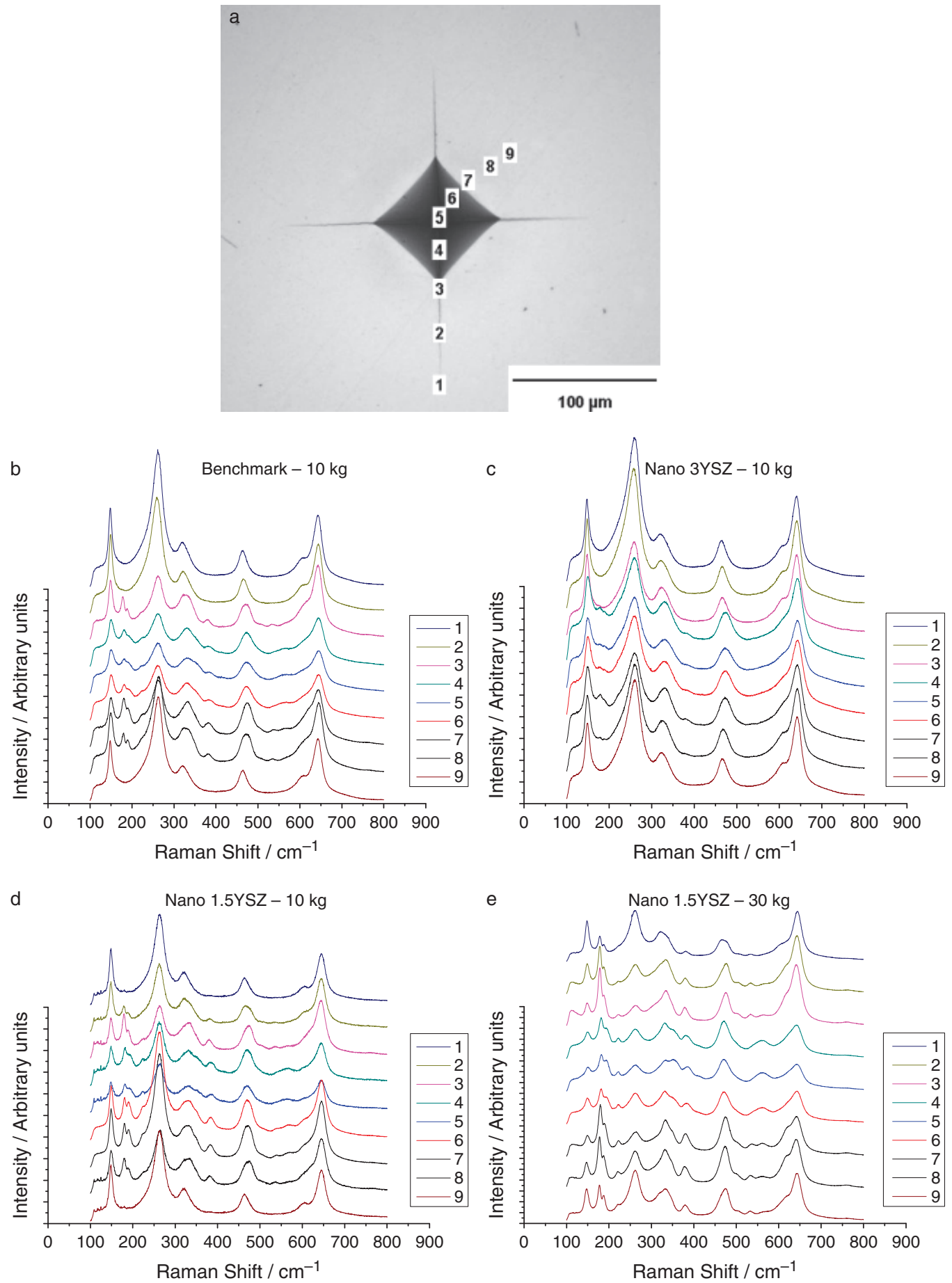

Fig. 12. Micro-Raman spectra results for 3 YSZ and 1.5 YSZ ceramics; (a) an optical microscopic image of the indent created on the benchmark 3 YSZ using a $10 \mathrm{~kg}$ load showing the locations from where the micro-Raman spectra were taken; (b) through (e) the micro-Raman data for the ceramics indicated, the load used to create the indents is also shown. 

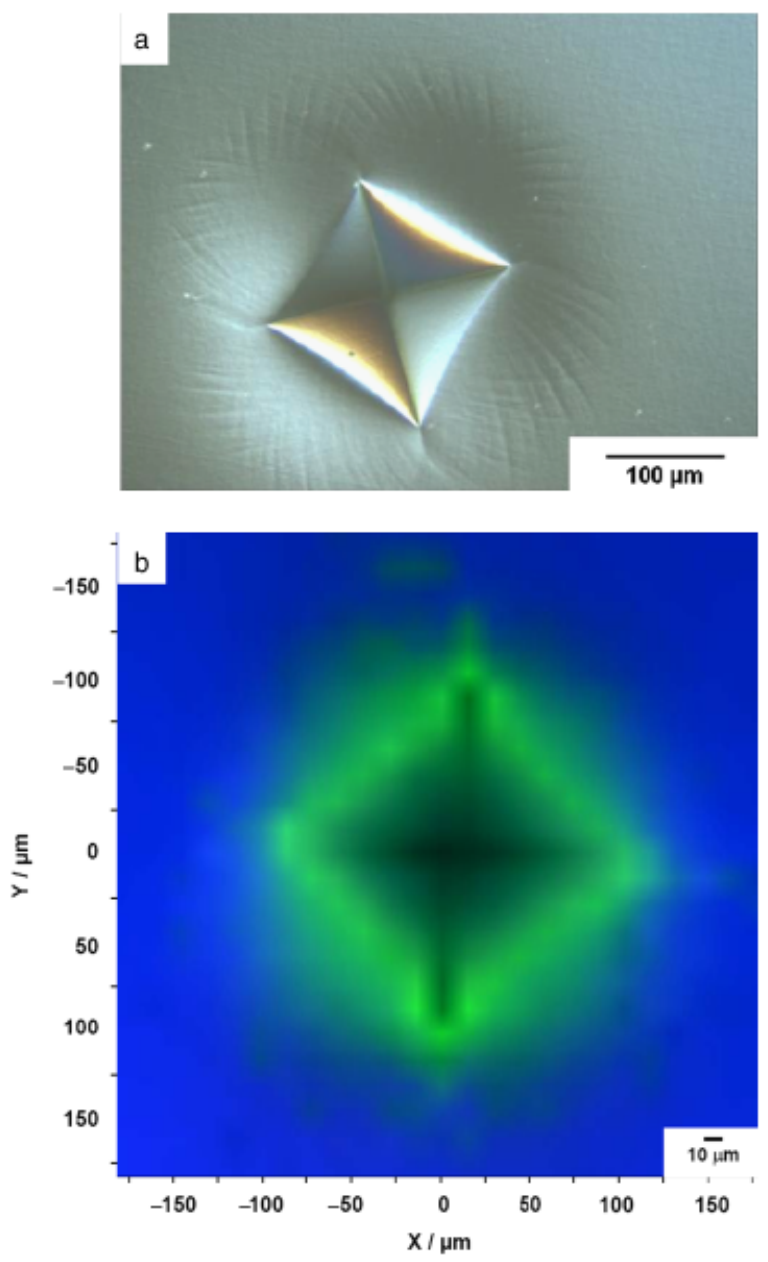

Fig. 13. (a) Differential interference contrast (DIC) optical microscope image and (b) micro-Raman map of an indent produced on a nano 1.5 YSZ ceramic using a load of $30 \mathrm{~kg}$. In (b) the green represents the presence of the monoclinic phase.

seen that the wear morphology is quite different for the nano- and submicrometer ceramics. The latter has undergone cracking while the wear morphology for the former shows mainly a fish-scale pattern formation and some plastic deformation. Similar plastic deformation and transcrystalline shear fracture of individual grains has been reported by Gahr et al. ${ }^{38}$ for fine-grain zirconia. The wear mechanism is quite different at the middle of the wear scar for both compared with the turn point region, Fig. 15. The benchmark 3 YSZ ceramic shows spalling of a surface layer leading to the formation of wear debris and pits, and hence increasing the degree of wear observed. The nano 3 YSZ ceramic shows the for-
Table III. Wear Testing Results for Samples Produced by Slip Casting

\begin{tabular}{lcccc}
\hline Sample & $\begin{array}{c}\text { No. of } \\
\text { cycles }\end{array}$ & $\begin{array}{c}\text { Applied } \\
\text { load (N) }\end{array}$ & $\begin{array}{c}\text { Wear } \\
\text { conditions }\end{array}$ & $\begin{array}{c}\text { Wear } \\
\text { volume } \\
\left(\mathbf{m m}^{\mathbf{3}}\right)\end{array}$ \\
\hline Benchmark & 100,000 & 20 & Dry & 1.07 \\
Nano 3 YSZ & 100,000 & 20 & Dry & 0.80 \\
Benchmark & 100,000 & 20 & Wet & 1.05 \\
Nano 3 YSZ & 100,000 & 20 & Wet & 0.64 \\
\hline
\end{tabular}

YSZ, yttria-doped partially stabilized zirconia.

mation of microcracks perpendicular to the sliding direction; similar microcracking has been reported for a $5.7 \mathrm{~mol} \%$ YSZ with a $180 \mathrm{~nm}$ grain size. ${ }^{35}$ Under wet wear, Fig. 16, it is clear that the surface detachment has occurred over a larger area for the benchmark ceramics while the surface damage to the nano $3 \mathrm{YSZ}$ sample was less severe and mainly showed the fish-scale pattern formation. XRD analysis revealed that there was no detectable formation of the monoclinic phase for the nano 3 YSZ ceramics under either set of wear conditions, while the benchmark submicrometer ceramics exhibited $\sim 2.5$ vol\% transformation under dry wear conditions and 8.1 vol\% after wet wear, ${ }^{\dagger}$ although others have failed to observe any transformation by XRD after wear testing in similar submicrometer 3 YSZ ceramics. ${ }^{35}$ Micro-Raman spectroscopy confirmed the presence of monoclinic in the benchmark samples after wear testing and its absence in the nanostructured ceramics.

Yttria-stabilized zirconia is well known for suffering from a phase transformation from tetragonal to monoclinic in the presence of water or water vapor, which deteriorates its properties. This hydrothermal degradation is accelerated at higher temperatures and is a major concern in applications where zirconia comes in contact with water, water vapor, or other water-containing fluids. Typical applications that are affected include bioimplants, for example femoral heads, knee implants, dental implants, and surgical tools, ferrules, thermal barrier coatings, solid oxide fuel cell (SOFC) components, etc. In most of these applications, high shear is

\footnotetext{
The actual degree of transformation may be even higher as it was difficult to focus the $\mathrm{X}$-rays on the wear scar. This result does confirm, however, the fact that there is increased transformation under wet wear conditions.
} 

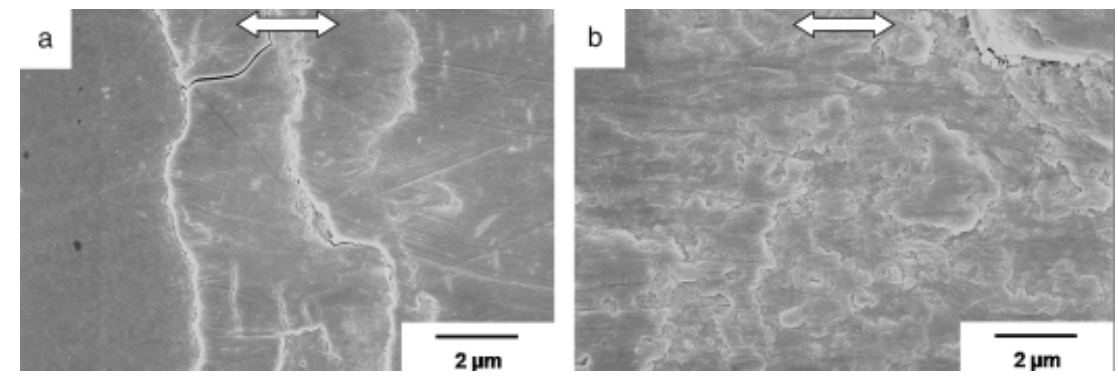

Fig. 14. Wear morphology at the turn point area after dry wear, (a) benchmark and (b) nano 3 YSZ. Arrows indicate the wear direction.

involved or the operating temperatures are very high, and hence the aging will occur at a faster rate.

Table IV summarizes the XRD data for the hydrothermal aging of some of the different YSZ ceramics at $140^{\circ} \mathrm{C}$ and $245^{\circ} \mathrm{C}$. It is immediately apparent that transformation begins to occur after as little as $30 \mathrm{~min}$ (the minimum time tested) for the submicrometer ceramic at $140{ }^{\circ} \mathrm{C}$ and that $73.5 \%$ had transformed after $168 \mathrm{~h}$. This is in reasonable agreement with the maximum transformation of $76.3 \%$ reported by Yamashita and Tsukuma ${ }^{39}$ for the aging of the same ceramic at the same temperature and the calculations of Thompson and Rawlings. ${ }^{40}$ The sample had completely disintegrated in the autoclave at the end of the $336 \mathrm{~h}$ ( 2 week) test. Although the nano 2 YSZ ceramic was displaying some transformation after $12 \mathrm{~h}$, there was no visible transformation at all for the nano 3 YSZ ceramic, even after the full 2-week period. Rather than prolong the tests (Chevalier et al. ${ }^{41}$ has calculated that $1 \mathrm{~h}$ of aging at $134^{\circ} \mathrm{C}$ and 2 bar is equivalent to 4 years in vivo aging, hence 2 weeks at $140^{\circ} \mathrm{C}$ and 4 bar is equivalent to more than 1300 years), to investigate this further, the temperature and pressure were raised in the autoclave to $245^{\circ} \mathrm{C}$ (the maximum temperature achievable) and 7 bar. The benchmark ceramic had completely disintegrated after as little as $1 \mathrm{~h}$ at this temperature, while the nano 3 YSZ ceramics remained completely unaffected in terms of exhibiting transformation for the full 2-week assessment period. The XRD results were fully confirmed by the micro-Raman analysis, which also failed to reveal any sign of the monoclinic phase in the nano 3 YSZ ceramics even after the full 2 weeks at $245^{\circ} \mathrm{C}^{27}$ Hardness and strength measurements on these ceramics also indicated that there was no significant change in their properties. This finding that the nano 3 YSZ ceramics appear to be completely immune to hydrothermal aging for up to 2 weeks at $245^{\circ} \mathrm{C} \mathrm{\&} 7$ bar, is the subject of a patent application. ${ }^{42}$

There is no single universally accepted mechanism to describe the hydrothermal degradation of zirconia but it is generally believed that water preferentially attacks regions of low yttria content. For example, it has been suggested that when conventional submicrometer $3 \mathrm{YSZ}$ is sintered at a temperature $>\sim 1300^{\circ} \mathrm{C}$, a heterogeneous distribution of yttria develops within the zirconia grains. ${ }^{43,44}$ Analysis has shown that the amount of yttria varies from $\sim 6 \mathrm{~mol} \%$ at the grain boundaries to $\sim 2 \mathrm{~mol} \%$ at the grain interiors. Because the bench-
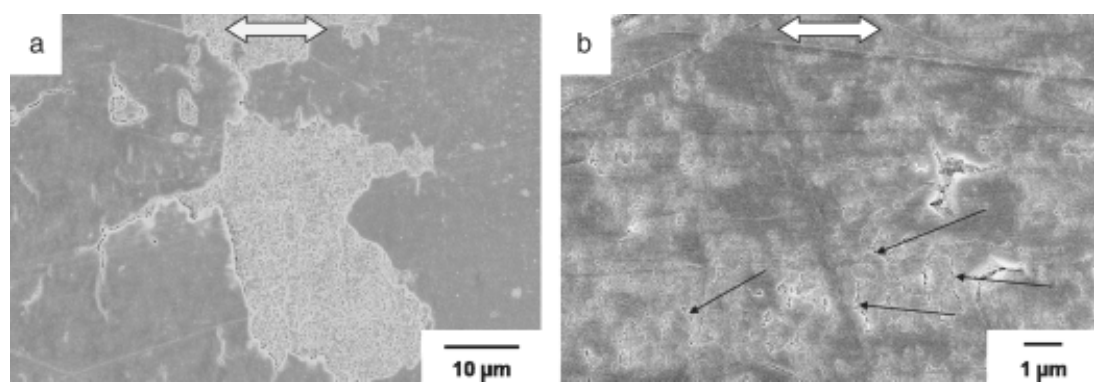

Fig. 15. Wear morphology at the middle of the wear zone after dry wear, (a) benchmark and (b) nano 3 YSZ. Arrows indicate the wear direction. 

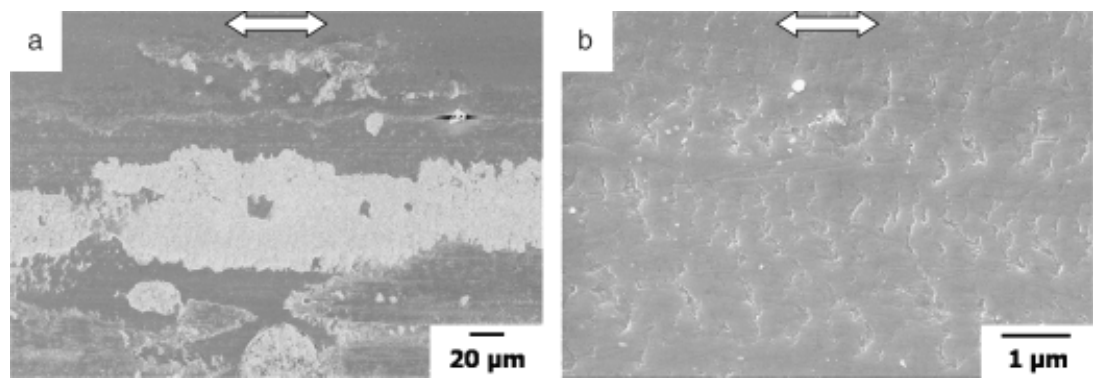

Fig. 16. Wear morphology at the middle of the wear scar after wet wear, (a) benchmark and (b) nano 3 YSZ. Arrows indicate the wear direction.

mark ceramic was sintered for $2 \mathrm{~h}$ at $1500^{\circ} \mathrm{C}$ in the present work, it can be assumed that water rapidly attacked the yttria-deficient grains converting them to the monoclinic phase. The limiting factor which decides the maximum transformation is therefore the fraction of yttria-depleted grains present in the sample after sinte-

\section{Table IV. Degree of Phase Transformation after Hydrothermal Aging for Samples Produced by Slip Casting}

\begin{tabular}{|c|c|c|c|c|c|}
\hline \multirow[b]{2}{*}{$\begin{array}{l}\text { Aging } \\
\text { time } \\
\text { (h) }\end{array}$} & \multicolumn{5}{|c|}{ Monoclinic content detected (vol\%) } \\
\hline & $\begin{array}{c}\text { Benchmark } \\
3 \mathrm{YSZ} \text { at } \\
140^{\circ} \mathrm{C}\end{array}$ & $\begin{array}{l}\text { Nano } 2 \\
\text { YSZ at } \\
140^{\circ} \mathrm{C}\end{array}$ & $\begin{array}{c}\text { Nano } \\
3 \mathrm{YSZ} \\
\text { at } 140^{\circ} \mathrm{C}\end{array}$ & $\begin{array}{c}\text { Benchmark } \\
3 \text { YSZ } \\
\text { at } 245^{\circ} \mathrm{C}\end{array}$ & $\begin{array}{l}\text { Nano } 3 \\
\text { YSZ at } \\
245^{\circ} \mathrm{C}\end{array}$ \\
\hline 0 & 0 & 0 & 0 & 0 & 0 \\
\hline 0.5 & 3.4 & - & 0 & - & 0 \\
\hline 1 & 4.2 & - & 0 & $\begin{array}{l}\text { Sample } \\
\text { disintegrated }\end{array}$ & 0 \\
\hline 2 & 10.7 & - & 0 & $\begin{array}{l}\text { Sample } \\
\text { disintegrated }\end{array}$ & 0 \\
\hline 4 & 17.7 & - & 0 & $\begin{array}{l}\text { Sample } \\
\text { disintegrated }\end{array}$ & 0 \\
\hline 8 & 34.1 & - & 0 & $\begin{array}{l}\text { Sample } \\
\text { disintegrated }\end{array}$ & 0 \\
\hline 16 & 55.5 & - & 0 & $\begin{array}{l}\text { Sample } \\
\text { disintegrated }\end{array}$ & 0 \\
\hline 24 & 65.9 & 12.7 & 0 & $\begin{array}{l}\text { Sample } \\
\text { disintegrated }\end{array}$ & 0 \\
\hline 48 & 69.7 & - & 0 & $\begin{array}{l}\text { Sample } \\
\text { disintegrated }\end{array}$ & 0 \\
\hline 120 & 70.2 & 22.2 & 0 & $\begin{array}{l}\text { Sample } \\
\text { disintegrated }\end{array}$ & 0 \\
\hline 168 & 73.5 & - & 0 & $\begin{array}{l}\text { Sample } \\
\text { disintegrated }\end{array}$ & 0 \\
\hline 336 & $\begin{array}{l}\text { Sample } \\
\text { disintegrated }\end{array}$ & - & 0 & $\begin{array}{l}\text { Sample } \\
\text { disintegrated }\end{array}$ & 0 \\
\hline
\end{tabular}

YSZ, yttria-doped partially stabilized zirconia. ring. Now, in the present work, the nano 3 YSZ samples were sintered at temperatures much lower than $1300^{\circ} \mathrm{C}$; $\mathrm{T} 1$, the peak value, was only $1150^{\circ} \mathrm{C}$. Of course, the fact that the primary particles were only $\sim 16 \mathrm{~nm}$ in size could mean that the value of $1300^{\circ} \mathrm{C}$ is itself lowered, nevertheless, it is believed reasonable to assume that there was no or minimal grain-boundary segregationinduced phase transformation (GBSIPT) occurring in the nanostructured samples. This assumption is currently being investigated further. A further factor believed to be helping to protect the nano 3 YSZ ceramics from hydrothermal aging is the fact that they are overstabilized due to a grain-size-induced phase boundary shifting mechanism. ${ }^{45,46}$

\section{Conclusions}

The high solids content but low viscosity YSZ nanosuspensions can be slip cast yielding $\sim 52 \%$ dense, very homogeneous, green bodies in sizes currently up to $60 \mathrm{~mm}$ in diameter. For success, it currently appears to be beneficial to use a very fine grade of plaster of Paris and an insert rather than machining to create the mold cavity. The current work is focusing on extending the size even further, up to $100 \mathrm{~mm}$ in diameter. For dry forming, it has been found that the combination of freeze-spray drying with the incorporation of a combustible additive can yield very flowable granulated nanopowders that are also able to crush at pressures as low as $250 \mathrm{MPa}$, within the range of most ceramic manufacturers. $\sim 54 \%$ dense and homogeneous green bodies can be formed. Green bodies can be successfully sintered to densities $>99.5 \%$ of the theoretical while retaining a mean grain size of $<100 \mathrm{~nm}$ using two-stage sintering provided that the green density of the body is in excess 
of $\sim 50 \%$ of the theoretical. Hybrid (microwave/conventional) heating enhances sintering, reducing both grain growth and the time at T2 by up to $90 \%$.

The strength of the sintered nanostructured ceramics has been found to be very similar to that of conventional submicrometer ceramics, viz. $\sim 1 \mathrm{GPa}$. Interestingly, the fracture mechanism is different; the nanostructured ceramics all resulted in failure via an intergranular fracture mode while it was transgranular for the benchmark, submicrometer ceramics. It is believed that it may be possible to achieve an even greater strength for the nanostructured ceramics once processing and the mean grain size have been optimized further. As far as toughness is concerned, it is believed that the combination of indentation and SCF results indicate that the nano $1.5 \mathrm{YSZ}$ ceramics may be best viewed as crack, or damage, initiation resistant rather than crack propagation resistant. Micro-Raman mapping has also been demonstrated to be a very effective technique to map the phase transformations in zirconia.

The wear mechanism of nanozirconia is controlled by microcracking and plastic deformation whereas in submicrometer, it is due to phase transformation and delamination; the former leads to a reduction in wear rates, particularly, according to the present work, under wet conditions. Perhaps the greatest property finding, however, was that the nano 3 YSZ ceramics appear to be completely immune to hydrothermal aging for up to 2 weeks at $245^{\circ} \mathrm{C}$ and $7 \mathrm{bar}$; conditions which see a conventional, commercial submicrometer ceramic disintegrate completely within $1 \mathrm{~h}$.

\section{References}

1. M. J. Mayo, "Processing of Nanocrystalline Ceramics from Ultrafine Particles," Int. Mater. Rev., 41 85-115 (1996).

2. F. Wakai, S. Sakaguchi, and Y. Matsuno, "Superplasticity of Yttria-Stabilized Tetragonal $\mathrm{ZrO}_{2}$ Polycrystals," Adv. Ceram. Mater., 1 259-263 (1986).

3. J. Karch and R. Birringer, "Nanocrystalline Ceramics: Possible Candidates for Net-Shape Forming," Ceram. Int., 16 291-294 (1990).

4. H. Hahn and R. S. Averback, "Low-Temperature Creep of Nanocrystalline Titanium (IV)," J. Am. Ceram. Soc., 74 2918-2921 (1991).

5. W. E. Kuhn, "Consolidation of Ultrafine Particles," Ultrafine Particles. ed. W. E. Kuhn. Wiley, New York, 41-103, 1963.

6. R. Würschum, S. Herth, and U. Brossmann, "Diffusion in Nanocrystalline Metals and Alloys-A Status Report," Adv. Eng. Mater., 5 365-372 (2003).

7. P. Mondal, A. Klein, W. Jaegermann, and H. Hahn, "Enhanced Specific Grain Boundary Conductivity in Nanocrystalline $\mathrm{Y}_{2} \mathrm{O}_{3}$-Stabilized Zirconia," Solid State Ionics, 118 331-339 (1999).

8. C. Demetry and X. Shi, "Grain Size-Dependent Electrical Properties of Rutile ( $\left.\mathrm{TiO}_{2}\right)$ ), Solid State Ionics, 118 271-279 (1999).

9. I. Kosacki, T. Suzuki, V. Petrovsky, and H. U. Anderson, "Electrical Conductivity of Nanocrystalline Ceria and Zirconia Thin Films," Solid State Ionics, 136-137 1225-1233 (2000).
10. J. Karch, R. Birringer, and H. Gleiter, "Ceramics Ductile at Low Temperature," Nature, 330 556-558 (1987).

11. T. H. Cross and M. J. Mayo, "Ceramic-Ceramic Diffusion Bonding Using Nanocrystalline Interlayers," Nanostruct. Mater., 3 163-168 (1993).

12. M. J. Mayo, R. W. Siegel, A. Narayanasamy, and W. D. Nix, "Mechanical Properties of Nanophase $\mathrm{TiO}_{2}$ as Determined by Nanoindentation," J. Mater. Res., 5 1073-1082 (1990).

13. J. R. Groza and R. J. Dowding, "Nanoparticulate Materials Densification," Nanostruct. Mater., 7 749-768 (1996).

14. M. A. Meyers, A. Mishra, and D. J. Benson, "Mechanical Properties of Nanostructured Materials," Prog. Mater. Sci., 51 427-556 (2006).

15. S. Shukla and R. Seal, "Mechanisms of Room Temperature Metastable Tetragonal Phase Stabilisation in Zirconia," Int. Mater. Rev., 50 [1] 45-64 (2005).

16. J. G. P. Binner and B. Vaidhyanathan, "Processing of Bulk Nanostructured Ceramics," J. Eur. Ceram. Soc., 28 1329-1339 (2008).

17. I. Santacruz, K. Annapoorani, and J. G. P. Binner, "Preparation of High Solids Content Nano Zirconia Suspensions," J. Am. Ceram. Soc., 91 [2] 398405 (2008).

18. J. G. P. Binner, B. Vaidhyanathan, and J. Wang, "A Comparative Study of Temperature Measurements During Microwave Processing," Proceedings of the 9th International Conference on Microwave and High Frequency Heating, Loughborough, U.K., 477-480 (2003).

19. H. Toraya, M. Yoshimura, and S. Somiya, "Calibration Curve for Quantitative Analysis of the Monoclinic-Tetragonal $\mathrm{ZrO}_{2}$ System by X-Ray Diffraction," J. Am. Ceram. Soc., 67 C 119-121 (1984).

20. G. R. Anstis, P. Chantikul, B. R. Lawn, and D. B. Marshall, "A Critical Evaluation of Indentation Techniques for Measuring Fracture Toughness: I, Direct Crack Measurements," J. Am. Ceram. Soc., 64 [9] 533-538 (1981).

21. J. Eichler, M. Hoffman, U. Eisele, and J. Rödel, "R-Curve Behaviour of 2YTZP With Submicron Grain Size,” J. Eur. Ceram. Soc., 26 3575-3582 (2006).

22. J. Lankford, "Indentation Microfracture in the Palmqvist Crack Regime: Implication for Fracture Toughness Evaluation by the Indentation Method," J. Mater. Sci. Lett., 1 493-495 (1982).

23. K. Niihara, R. Morena, and D. P. H. Hasselman, "Evaluation of $k_{\text {ic }}$ of Brittle Solids by the Indentation Method with Low Crack-To-Indent Ratios," J. Matter. Sci. Lett., 1 13-16 (1982).

24. K. Niihara, "A Fracture Mechanics Analysis of Indentation-Induced Palmqvist Crack in Ceramics," J. Mater. Sci. Lett. 2 221-223 (1983).

25. J. Chevalier, "What Future for Zirconia as a Biomaterial?," Biomaterials, 27 535-543 (2006).

26. J. G. P. Binner, B. P. C. Raghupathy, B. Vaidhyanathan, and K. Annapoorani, "Granule Strength Reduction," U.K. Patent Appl. No. 0818851.8. Filed October 2008.

27. A. Paul, "Processing and Properties of Nanostructured Zirconia Ceramics," Ph.D. Thesis, Loughborough University, 2008.

28. O. Vasylkiv, Y. Sakka, and V. V. Skorokhod, "Low-Temperature Processing and Mechanical Properties of Zirconia and Zirconia-Alumina Nanoceramics," J. Am. Ceram. Soc., 86 [2] 299-304 (2003).

29. J. Luo, D. P. Almond, and R. Stevens, "Ionic Mobilities and Association Energies from an Analysis of Electrical Impedance of $\mathrm{ZrO}_{2}-\mathrm{Y}_{2} \mathrm{O}_{3}$ Alloys," J. Am. Ceram. Soc., 83 [7] 1703-1708 (2000).

30. D. Huang, K. R. Venkatachari, and G. C. Stangle, "Influence of Yttria Content on the Preparation of Nanocrystalline Yttria-Doped Zirconia," J. Mater. Res., 10 [3] 762-773 (1995).

31. B. A. Cottom and M. J. Mayo, "Fracture Toughness of Nanocrystalline $\mathrm{ZrO}_{2}-3 \mathrm{Mol} \% \mathrm{Y}_{2} \mathrm{O}_{3}$ Determined by Vickers Indentation," Scr. Mater., 34 [5] 809-814 (1996).

32. A. Bravo-Leon, Y. Morikawa, M. Kawahara, and M. J. Mayo, "Fracture Toughness of Nanocrystalline Tetragonal Zirconia with Low Yttria Content," Acta Mater., 50 [18] 4555-4562 (2002).

33. J. Wang, M. Rainforth, and R. Stevens, "The Grain Size Dependence of the Mechanical Properties in TZP Ceramics," Br. Ceram. Trans. J. 88 1-6 (1988).

34. M. S. Kaliszewski, et al., "Indentation Studies on $\mathrm{Y}_{2} \mathrm{O}_{2}-$ Stabilized $\mathrm{ZrO}_{2}$ : I, Development of Indentation-Induced Cracks," J. Am. Ceram. Soc., 77 [5] 1185-1193 (1994).

35. Y. He, L. Winnubst, A. J. Burggraaf, H. Verweij, P. G. Th. Van der Varst, and B. de, "With, Influence of Porosity on Friction and Wear of Tetragonal Zirconia Polycrystal," J. Am. Ceram. Soc., 80 [2] 377-380 (1997). 
36. C. T. Yang and W. J. Wei, "Effects of Material Properties and Testing Parameters on Wear Properties of Fine-Grain Zirconia (TZP)," Wear, 242 [1-2] 97-104 (2000).

37. S. W. Lee, S. M. Hsu, and M. C. Shen, "Ceramic Wear Maps: Zirconia," J. Am. Ceram. Soc., 76 [8] 1937-1947 (1993).

38. K. H. Z. Gahr, W. Bundschuh, and B. Zimmerlin, "Effect of Grain Size on Friction and Sliding Wear of Oxide Ceramics," Wear, 162-164 [1] 269-279 (1993).

39. I. Yamashita and K. Tsukuma, "Phase Separation and Hydrothermal Degradation of $3 \mathrm{Mol} \% \mathrm{Y}_{2} \mathrm{O}_{3}-\mathrm{Zro}_{2}$ Ceramics," J. Ceram. Soc. Jpn., 113 [8] 530-533 (2005).

40. I. Thompson and R. D. Rawlings, "Mechanical Behaviour of Zirconia and Zirconia-Toughened Alumina in a Simulated Body Environment," Biomaterials, 11 505-508 (1990).

41. J. Chevalier, J. M. Drouin, and B. Cales, "Low Temperature Ageing Behavior of Zirconia Hip Joint Heads," Bioceramics, Vol. 10. eds., L. Sedel and C. Rey. Elsevier Science, Amsterdam, The Netherlands, 135-138, 1997.
42. J. G. P. Binner, B. Vaidhyanathan, A. Paul, and K. Annapoorani, "Nanostructured Ceramics," U.K. Patent Appl. No. 0821674.9. Filed November 2008.

43. K. Matsui, H. Horikoshi, N. Ohmichi, M. Ohgai, H. Yoshida, and Y. Ikuhara, "Cubic-Formation and Grain-Growth Mechanisms in Tetragonal Zirconia Polycrystal," J. Am. Ceram. Soc., 86 [8] 1401-1408 (2003).

44. K. Matsui, N. Ohmichi, M. Ohgai, H. Yoshida, and Y. Ikuhara, "Effect of Alumina-Doping on Grain Boundary Segregation-Induced Phase Transformation in Yttria-Stabilized Tetragonal Zirconia Polycrystal," J. Mater. Res., 21 [9] 2278-2289 (2006).

45. A. Suresh, M. J. Mayo, W. D. Porter, and C. J. Rawn, "Crystallite and GrainSize-Dependent Phase Transformations in Yttria-Doped Zirconia," J. Am. Ceram. Soc., 86 [2] 360-362 (2003).

46. B. Vaidhyanathan and J. G. P. Binner, "Novel Processing of Nanostructured Ceramics Using Microwaves," Proceedings of the Fourth World Congress on Microwave and Radio Frequency Applications. ed. R. L. Schulz and D. C. Folz, The Microwave Working Group Ltd., Arnold, MD, 192-198, 2004. 